\title{
Surveillance nursing diagnoses, ongoing assessment and outcomes on in-patients who suffered a cardiorespiratory arrest
}

\author{
Diagnósticos de enfermagem de vigilância, avaliação contínua e resultados em pacientes que \\ sofreram uma parada cardiorrespiratória \\ Diagnósticos enfermeros de vigilancia, evaluación en curso y resultados en pacientes hospitalizados \\ que sufrieron paro cardiorrespiratorio
}

\author{
Maria-Eulàlia Juvé-Udina ${ }^{1,2}$, Núria Fabrellas-Padrés ${ }^{1,2}$, Jordi Adamuz-Tomás ${ }^{2,3}$, Sònia Cadenas-González ${ }^{4}$, Maribel \\ Gonzalez-Samartino ${ }^{1,2}$, Laura de la Cueva Ariza ${ }^{1,2}$, Pilar Delgado-Hito ${ }^{1,2}$
}

How to cite this article:

Juvé-Udina ME, Fabrellas-Padrés N, Adamuz-Tomás J, Cadenas-González S, Gonzalez-Samartino M, de la Cueva Ariza L, et al. Surveillance nursing diagnoses, ongoing assessment and outcomes on in-patients who suffered a cardiorespiratory arrest. Rev Esc Enferm USP. 2017; 51:e03286. DOI: http://dx.doi.org/10.1590/S1980-220X2017004703286

\author{
${ }^{1}$ University of Barcelona, School of \\ Nursing, Barcelona, Catalonia, Spain. \\ ${ }^{2}$ Institute of Research, Barcelona, \\ Catalonia, Spain. \\ ${ }^{3}$ University Ramon Llull, Blanquerna, School \\ of Nursing, Barcelona, Catalonia, Spain. \\ ${ }^{4}$ Germans Trial I Pujol University \\ Hospital, Department of Nursing, \\ Barcelona, Catalonia, Spain.
}

\section{Corresponding author:}

Maria-Eulàlia Juvé Udina

Universitat de Barcelona, IDIBELL

Institute of Research

Campus de Bellvitge, Escola

Universitària d'Infermeria

Departament d'Infermeria

Fonamental i Medicoquirúrgica

Feixa Llarga s/n

08907 Hospitalet de Llobregat, Barcelona, Spain ejuve@ub.edu

\begin{abstract}
Objective: The purposes of this study were to examine the frequency of surveillanceoriented nursing diagnoses and interventions documented in the electronic care plans of patients who experienced a cardiac arrest during hospitalization, and to observe whether differences exist in terms of patients' profiles, surveillance measurements and outcomes. Method: A descriptive, observational, retrospective, cross-sectional design, randomly including data from electronic documentation of patients who experienced a cardiac arrest during hospitalization in any of the 107 adult wards of eight acute care facilities. Descriptive statistics were used for data analysis. Two-tailed p-values are reported. Results: Almost $60 \%$ of the analyzed patients' e-charts had surveillance nursing diagnoses charted in the electronic care plans. Significant differences were found for patients who had these diagnoses documented and those who had not in terms of frequency of vital signs measurements and final outcomes. Conclusion: Surveillance nursing diagnoses may play a significant role in preventing acute deterioration of adult in-patients in the acute care setting.
\end{abstract}

\section{DESCRIPTORS}

Nursing Diagnosis; Heart Arrest; Standardized Nursing Terminology; Surveillance; Vital Signs. 


\section{INTRODUCTION}

In the last two decades, acute care wards have progressively become intensive-like care settings. Most admitted patients are aged, suffer multiple major comorbidities and require proficient nursing care to prevent, promptly diagnose and manage life-threatening complications. Evidence indicates that a significant proportion of potentially preventable acute in-patient deaths are related to adverse events, and that up to $80 \%$ of in-hospital cardiac arrests are predictable $^{(1-2)}$. Both clinical and organizational factors have influence over preventable adverse events leading to cardiac arrest, unplanned admission to intensive care units (ICU) or unexpected deaths ${ }^{(3-4)}$. Clinical causes refer to circumstances such as lack of adequate ongoing assessment of patients' status and progress, or missed cues and triggers initiating a cascade to severe complications. Organizational factors include circumstances such as poor communication among clinicians or delays in diagnosis, treatment or referral ${ }^{(3-4)}$. Providing optimal care and preventing adverse events by recognizing patients' deterioration early have been referred to as a main topic and it also represents an ethical mandate ${ }^{(5-6)}$. Equally, nursing surveillance or the process "through which nurses monitor, evaluate and act upon emerging indicators of a patient's change in status"(6), has also been focused on in during the last decade. This process of ongoing vigilant observation, data collection, interpretation and recognition of changes in patients' status should lead to prioritizing patients' problems and decision making on the interventions to perform in order to curb the cascade to serious adverse events ${ }^{(7-8)}$.

Bedside nurses have been acknowledged as a "de facto surveillance system overseeing the patient care experience"(9). Nurses' expertise to communicate and document patient's status, problems and progress is a significant issue in patients' safety ${ }^{(10)}$, thus researchers are exploring the relationship between health records and failure to rescue or in-patients' mortality ${ }^{(11-13)}$. Electronic health records (EHR) have been found to be useful for communicating nurses' concerns on patients' progress and to record systematic bedside observations of patients in acute care wards, including measuring vital signs which are mandatory for early detection of deterioration. However, "the relationship between EHR and nurse-to-nurse communication and therefore to patient safety and failure to rescue are not well understood"(14). Nurses apply clinical judgment and make decisions in the surveillance process; it would consequently be logical to expect that EHR include nursing care plans to reflect nurses' judgments on patient status and progress, and the interventions to achieve health outcomes. In this sense, the literature on nursing diagnoses is vast, mainly on the NANDA International Classification because this standardized language has been researched for a long time ${ }^{(15)}$.

The current study focuses on the use of nursing diagnoses and interventions from an interface terminology termed ATIC ${ }^{(16)}$. The acronym ATIC reflects six key concepts in Catalan spelling: Architecture, Terminology, Interface, Information, Nursing (Infermeria), and Knowledge (Coneixement). In this controlled vocabulary, terms and concepts result from the study of the natural language nurses use in their daily practice, subsequently examined for theoretical refinement. The philosophical basis of this terminology, the inductive validity of its structure, validity metrics, usability and implementation in practice have been previously studied ${ }^{(17-18)}$.

The constructs Nursing diagnosis and Nursing intervention within the ATIC framework were based on an eclectic and pragmatic approach (Chart 1). This framing provided the rationale for ATIC to consider surveillance-oriented nursing diagnoses (SONDs), which are conceived as clinical judgments on the ongoing status of an individual (or group) at risk for progression to severe harm or life-threatening conditions. They are focused on nursing vigilance and prevention of patients' deterioration, including patients' potential progression to worsening states and occurrence or recurrence of serious adverse events. When included in a patient's care plan, they should be considered the patient's main problem(s), irrespective of the presence of other nursing diagnoses that may also be significant, and should orient the provision of related nursing interventions to assure an ongoing assessment of the patient'status and preventive interventions to avoid further potential harm ${ }^{(16-17)}$.

The purposes of this study were to examine the frequency of SONDs and interventions documented in the EHR of patients who experienced cardiac arrest during hospitalization, and to observe whether differences exist in terms of patients' profile, surveillance measurements and outcomes.

Chart 1 - Definitions of the Nursing diagnosis and nursing intervention concepts in ATIC.

\begin{tabular}{|c|c|}
\hline Nursing diagnosis & Nursing Intervention \\
\hline $\begin{array}{l}\text { A nursing diagnosis is a clinical judgment - or the } \\
\text { conclusion of several judgments - on the health } \\
\text { status of an individual (or group), and the actual } \\
\text { or potential consequences and reactions within } \\
\text { the different dimensions of the individual and their } \\
\text { integrality, in the context of their environment and } \\
\text { particular Experience, and within the scope of } \\
\text { professional nursing accountability, including shared } \\
\text { responsibility with the care beneficiaries and with other } \\
\text { healthcare providers }{ }^{(16-17)} \text {. }\end{array}$ & $\begin{array}{l}\text { A nursing intervention is a prescription of nursing care } \\
\text { that derives from the diagnosis of a patient's problem } \\
\text { or response and reflects nursing management for its } \\
\text { prevention, solving or palliation. Nursing interventions } \\
\text { do not include the description of procedures, rather } \\
\text { they are care prescription statements that may be } \\
\text { detailed by adding activities or specifications aimed } \\
\text { at clarifying or informing remarkable aspects of } \\
\text { that intervention to assure patient safety, quality or } \\
\text { continuity of care, or to respond to regulations, legal, } \\
\text { ethical or cost-efficiency requirements }{ }^{(18)} \text {. }\end{array}$ \\
\hline
\end{tabular}




\section{METHOD}

This study applied a multi-center, descriptive, cross-sectional design based on a 4- year retrospective evaluation of data collected from the electronic health records (EHR) of patients admitted to public hospitals in Catalonia (Spain). The setting of the inquiry included adult medical, surgical and combined medical-surgical units pertaining to three large metropolitan tertiary centers, three urban university facilities and two community hospitals (average of 460 beds, range 100-1100). Electronic nursing records from adult patients who experienced an in-ward cardiac arrest were considered eligible. A list containing the episode number of these patients and their conditions for admission was obtained from the EHR using Standardized Query Language (SQL) queries. Those patients admitted for palliative care purposes were excluded. The remaining candidate electronic records were randomly selected by means of applying a random number list. Sample size was calculated for a maximum uncertainty estimated proportion $(\mathrm{P}=0.50)$, 95\% confidence level $(\alpha=.05)$ and .05 precision $(i=0.5)$. Sample size resulted in 384 objects of study (e-charts). Assuming $15 \%$ potentially missed cases, the $\mathrm{Na}=\mathrm{N}[1 /$ $(1-R)$ ] formula was applied, resulting in a final sample size of 449 study objects.

Measures included patients' profile, SONDs, surveillance interventions and final outcomes. We also considered patient age, gender, condition for admission and age-adjusted Charlson comorbidity index (AACI). The AACI is a prognostic tool to measure disease burden and predict mortality, considering the number and type of major chronic conditions and weighting age decades. ICU stay before ward admission and the number of days since ward admission to cardiac arrest were also studied as variables in defining patient profiles.

SONDs documented in the e-care plans were considered as previously defined. Dichotomous identification of the variable and documented diagnostic labels were considered.

Surveillance intervention considered the assessment of basic physiological parameters (ABPP), the frequency of measurements and the length of time from last measurement to the cardiac arrest, as follows: ABPP was defined as the documentation of mental status (MS) using either the Glasgow Coma Scale, a categorized list of mental status in the e-flow sheet or as a narrative note; heart rate (HR); both systolic and diastolic blood pressure (BP); respiratory rate $(\mathrm{RR})$; oxygen saturation ( $\mathrm{SpaO} 2)$; temperature $(\mathrm{T})$; urine output (UO) or micturition (Mi); and when indicated, capillary glycemia (CG).

The frequency pattern of ABPP measurement referred to the documented interval of time between vital sign measurements during the 24 hours previous to the event. In our context, nurses occasionally use an interval to measure selected vital signs (MS, BP, HR, RR, $\mathrm{SpaO}_{2}$ ) and a different interval for other measurements ( $\mathrm{T}, \mathrm{UO}, \mathrm{Mi}, \mathrm{CG}$ ). We considered the selected ABPP interval for the purposes of this study.

The surveillance measure used to reflect the number of hours was length of time from the last measurement to the event including hourly quarters, from the last assessment of MS, BP and HR, BP and HR, MS and BP, or MS and HR, to the documented detection time of the patient experiencing a cardiac arrest.

Deceased patients after resuscitation efforts, ICU admission of the patient after cardiopulmonary resuscitation in the ward, and continuity of care in the unit after resuscitation maneuvers were selected as final outcomes.

The research project obtained institutional board and ethics committee approval. The researchers collected the data using a blinded retrieval system to protect patients' data confidentiality (TOAD for Oracle v.10, Quest Software Inc., Aliso Viejo, California); meaning that the SONDs documented by nurses were obtained by means of SQL queries launched into the nursing care planning section of the EHR, and lastly these data were exported to an Excel spreadsheet (Microsoft, Redmond, VA). The researchers used the same method to obtain data to illustrate patients' profiles, documented surveillance measures and final outcome. The data analyses were performed using the statistical functions of SPSS v15 (SPSS, Chicago, IL). Depending on the properties of the data, frequencies in percentages, means and standard deviation were calculated for description. Differences between groups were analyzed using the chi-square test for categorical variables, while we used the Student's t-test or Mann-Whitney $U$ test for continuous variables, depending on the results of the Kolmogorov- Smirnov normality test. $\mathrm{P}$-values less than .05 were considered statistically significant. All reported $\mathrm{p}$-values are 2 -tailed.

\section{RESULTS}

In this study, data were collected from 492 nursing e-documents of patients who had suffered a cardiac arrest in any of the adult wards ( $34.4 \%$ medical units, $33.3 \%$ surgical floors, and $32.3 \%$ combined medical-surgical wards) of eight acute care facilities. The review process of data prior to analyses allowed for identifying 42 lost cases, mainly due to a "Do-not-resuscitate" documented medical order within the 24 hours previous to the patient's cardiac arrest $(n=38)$, while four cases were lost due to missing data. Thus, the final analysis included data from $450 \mathrm{EHR}$.

Mean patient age was 75 years (range 31-98), and $52.4 \%$ were male patients. Mean AACI was 6.9 (SD 2.3). Patient condition for admission included: cardio-circulatory (23.7\%), respiratory $(13.0 \%)$, neurology $(11.7 \%)$, trauma (11.4\%), digestive (8.7\%), infectious (8.3\%), hematology or immunology (7.4\%), oncology (6.55), nephrology or urinary (4.8\%), metabolic (3.0\%) and other conditions (1.3\%). Just $16 \%$ of patients had been treated in the intensive care setting before being admitted to a ward. From the analyzed sample, 317 patients did not survive the cardiac arrest (70\%), 69 patients were transferred to ICU after resuscitation in the ward (15\%), and 64 patients were kept in care in the same ward after resuscitation (14\%).

Analysis on the frequency of SOND documented in the EHR resulted in $58 \%$ of patients' charts (mean age 76 ; mean AACI 6.8) with this type of diagnoses documented $(\mathrm{n}=261)$. Of these patients' care plans, $31 \%$ contained more 
than one SOND. On the other hand, 182 e-charts had no SOND considered in the care plan, and the remaining seven patients' e-records did not contain any care plan (1.5\%).

Most of these SONDs represent acute or critical potential complications, and are mostly cardio-circulatory, respiratory and infectious. Risk for arrhythmia (21.4\%), Risk for acute pulmonary edema, Risk for atelectasis and Risk for sepsis (12.6\% respectively) were the most frequent e-charted SONDs. Table 1 displays the ranking of the most frequently documented SONDs.

Table 1 - Ranking of surveillance-oriented e-charted nursing diagnoses - Catalonia, Spain, 2012-2016.

\begin{tabular}{|c|c|c|}
\hline Surveillance-oriented nursing diagnoses & $\mathbf{N}$ & $\%$ \\
\hline Risk of arrhythmia & 56 & 21.4 \\
\hline Risk of acute pulmonary edema & 33 & 12.6 \\
\hline Risk of atelectasis & 33 & 12.6 \\
\hline Risk of sepsis & 33 & 12.6 \\
\hline Risk of arrhythmia progression/recurrence & 25 & 9.5 \\
\hline Risk of ischemia/hemorrhage progression/recurrence & 25 & 9.5 \\
\hline Risk of pulmonary aspiration & 21 & 8.0 \\
\hline Risk of hemorrhage progression/recurrence & 21 & 8.0 \\
\hline Risk of hypovolemia & 20 & 7.6 \\
\hline Risk of ischemia progression/recurrence & 17 & 6.5 \\
\hline Risk of increased intracranial pressure & 17 & 6.5 \\
\hline Risk of vasospasm & 13 & 4.9 \\
\hline Risk of hypovolemic shock & 10 & 3.8 \\
\hline Risk of respiratory failure progression/recurrence & 9 & 3.4 \\
\hline Risk of respiratory failure & 7 & 2.6 \\
\hline Risk of hemorrhage & 5 & 1.9 \\
\hline Risk of ischemia/hemorrhage & 5 & 1.9 \\
\hline Risk of septic shock & 5 & 1.9 \\
\hline Risk of systemic inflammatory response syndrome & 5 & 1.9 \\
\hline Risk of airway obstruction & 4 & 1.5 \\
\hline Risk of cardiogenic shock & 4 & 1.5 \\
\hline Risk of hyper/hypovolemia & 4 & 1.5 \\
\hline
\end{tabular}

In regard to patients' profiles, no statistically significant differences were found between SOND and NO SOND groups in terms of gender and AACI $(p>0.5)$. Neither differences were identified when considering previous ICU stay $(p=0.07)$, or the number of days from ward admission to cardiac arrest $(p=0.9)$. Nevertheless, age was found to be lower in the SOND group.
Distribution data of conditions for admission were balanced, except for the case of cardiovascular which was more frequent in the SOND group ( $\mathrm{p}<0.001$ ), and inversely for trauma and neurologic conditions which were more common in the NO SOND group $(\mathrm{p}<0.001)($ Table 2$)$.

Table 2 - Participants characteristics in each group and final outcomes - Catalonia, Spain, 2012-2016.

\begin{tabular}{|c|c|c|c|c|c|}
\hline \multirow{2}{*}{$\begin{array}{l}\text { SOND Group } \\
\text { Variable }\end{array}$} & \multicolumn{5}{|c|}{ No SOND Group } \\
\hline & Mean & SD & Mean & SD & p-value \\
\hline Age & 73.01 & (13.7) & 78.18 & (12.3) & 0.001 \\
\hline \multirow[t]{2}{*}{$\mathrm{AACl}$} & 6.83 & $(2.3)$ & 7.01 & $(2.15)$ & 0.540 \\
\hline & $\mathbf{N}$ & $\%$ & $N$ & $\%$ & p-value \\
\hline Male Gender & 143 & 54.8 & 93 & 49.4 & 0.504 \\
\hline Previous ICU stay & 54 & 21.0 & 28 & 11.4 & 0.074 \\
\hline $\begin{array}{l}\text { Conditions for admission } \\
\text { Cardiovascular }\end{array}$ & 85 & 32.5 & 23 & 12.1 & $<0.001$ \\
\hline Respiratory & 30 & 11.5 & 29 & 15.3 & 0.428 \\
\hline Neurologic & 48 & 18.3 & 7 & 3.7 & $<0.001$ \\
\hline Trauma & 13 & 4.9 & 41 & 21.6 & $<0.001$ \\
\hline Digestive & 19 & 7.2 & 19 & 10.0 & 0.483 \\
\hline Infectious & 17 & 6.5 & 20 & 10.5 & 0.341 \\
\hline Hematology & 21 & 8.0 & 11 & 5.8 & 0.619 \\
\hline Oncology & 10 & 3.8 & 17 & 8.9 & 0.178 \\
\hline Nephrourinary & 10 & 3.8 & 15 & 7.9 & 0.158 \\
\hline Metabolic & 8 & 3.0 & 6 & 3.1 & 0.959 \\
\hline Other & 0 & 0.0 & 1 & 0.5 & 0.419 \\
\hline Outcome & $N$ & $\%$ & $\mathbf{N}$ & $\%$ & p-value \\
\hline Death & 154 & 59.0 & 163 & 86.2 & $<0.001$ \\
\hline Transferred to ICU & 58 & 22.2 & 11 & 5.8 & 0.001 \\
\hline Continuity of care at floor & 49 & 18.7 & 15 & 7.9 & 0.035 \\
\hline
\end{tabular}

All patients had heart rate and blood pressure documented in the electronic flow sheet. Most e-charts also documented patient temperature (99.6\%), mental status (99.2\%), micturition (93.1\%), $\mathrm{SpaO}_{2}(89.5 \%)$ and urine output (75.9\%). Only a few e-flow sheets contained respiratory rate measurements (26.1\%). Capillary glycaemia was documented in half of the reviewed cases (51.2\%). No differences between the two groups were identified in relation to the ABPP when considering mental status $(p=0.81)$, heart rate $(\mathrm{p}=1)$, blood pressure $(\mathrm{p}=1)$, temperature $(\mathrm{p}=0.39)$, micturition $(p=0.05)$ and capillary glycaemia $(p=0.28)$. However, minor statistically significant differences were observed for $\mathrm{SpaO}_{2}(\mathrm{p}=0.047)$, while major significant differences could be observed for respiratory rate $(\mathrm{p}<0.001)$ and urine output measurements $(\mathrm{p}=0.003)$. 
Patients with SOND documented in the e-care plan were more prone to have their $\mathrm{ABPP}$ measured at intervals not exceeding six hours (75.1\%). Inversely, most patients (84.1\%) who did not have any SOND included in their care plans had their $\mathrm{ABPP}$ measured with frequencies ranging from every seven to twelve hours (Table 3). Likewise, when considering conditions for admission and frequency of ABPP measurements higher or lower than six hours, we found that all groups distributed similarly except for the case of patients with trauma $(\mathrm{p}=0.003)$ and neurological conditions $(\mathrm{p}=0.013)$.

Table 3 - Main findings for surveillance measurements - Catalonia, Spain, 2012-2016.

\begin{tabular}{|c|c|c|c|c|c|}
\hline \multirow{2}{*}{$\begin{array}{l}\text { SOND Group } \\
\text { Variable }\end{array}$} & \multicolumn{4}{|c|}{ No SOND Group } & \multirow{2}{*}{ p-value } \\
\hline & Mean & SD & Mean & SD & \\
\hline Mental status & 259 & 99.2 & 187 & 99.0 & 0.816 \\
\hline Heart rate & 261 & 100 & 189 & 100 & 1.000 \\
\hline Blood pressure & 261 & 100 & 189 & 100 & 1.000 \\
\hline Respiratory rate & 112 & 42.9 & 9 & 4.71 & $<0.001$ \\
\hline $\mathrm{SpaO}_{2}$ & 243 & 93.2 & 159 & 84.2 & 0.047 \\
\hline Temperature & 259 & 99.2 & 189 & 100 & 0.395 \\
\hline Capillary glycaemia & 142 & 54.7 & 88 & 46.5 & 0.284 \\
\hline Urine output & 218 & 83.5 & 124 & 65.6 & 0.003 \\
\hline Micturition & 251 & 96.2 & 169 & 89.5 & 0.058 \\
\hline \multicolumn{6}{|c|}{ Frequency of measurements } \\
\hline Every 12 hours or more & 6 & 2.2 & 91 & 48.0 & $<0.001$ \\
\hline Every 9-10 hours & 2 & 0.7 & 23 & 12.1 & $<0.001$ \\
\hline Every $7-8$ hours & 57 & 21.8 & 45 & 23.9 & 0.842 \\
\hline Every 5-6 hours & 88 & 33.7 & 25 & 13.3 & 0.001 \\
\hline Every 3-4 hours & 75 & 28.7 & 5 & 2.5 & $<0.001$ \\
\hline Every $1-2$ hours & 33 & 12.6 & 0 & 0.0 & $<0.001$ \\
\hline
\end{tabular}

Frequency of ABPP showed a balanced distribution; 49.4\% of patients had their ABPP measured with a frequency exceeding six hours (every seven to twelve hours), while $50.6 \%$ patients $(n=228)$ received more intensive nursing surveillance, having their ABPP performed at a frequency not exceeding six hours (every one to six hours). Statistically significant differences were found among survivors and deceased patients having their $\mathrm{ABPP}$ evaluated at intervals equal or lower than every 6 hours. At intervals not exceeding every 6 hours of ABPP measurement, $62.7 \%$ of cases resulted in patients' survival, while only $37.5 \%$ of patients survived the fatal event at higher intervals $(p=0.02)$. Significant differences were also observed between SOND and NO SOND groups (Table 4).
Table 4 - Surveillance diagnoses, frequency of ABPP measurement and patient outcomes - Catalonia, Spain, 2012-2016.

\begin{tabular}{lccccc}
\hline \multirow{2}{*}{ SOND Group } & \multicolumn{5}{c}{ No SOND Group } \\
\cline { 2 - 6 } & $\mathbf{N}$ & $\%$ & $\mathbf{N}$ & $\%$ & $\mathbf{p}$ \\
\hline Frequency of ABPP measurements & 65 & 24.9 & 159 & 84.2 & $<0.001$ \\
Exceeding 6 hours & 196 & 75.1 & 30 & 15.6 & $<0.001$ \\
\hline Less than 6 hours & & & & & \\
\hline Outcome & 154 & 59.0 & 163 & 86.2 & $<0.001$ \\
Deceased & 58 & 22.2 & 11 & 5.8 & 0.001 \\
Transferred to ICU & 49 & 18.7 & 15 & 7.9 & 0.035 \\
Continuity of care at floor & & & & & \\
\hline
\end{tabular}

Mean time from the last measurements of ABPP to the documented cardiac arrest code was 3.6 hours (SD 2.6), ranging from half an hour to almost twelve hours. Additionally, according to data, mean length of time from the last measurement of ABPP to the documented event was 2.8 hours (SD 2.0) in the SOND group and 4.9 hours (SD 2.9) in the NO SOND group ( $<0.001)$. Finally, with regard to the outcomes, the proportion of patients who died was lower in the SOND group $(\mathrm{p}<0.001)$, and the number of survivors transferred to ICU $(\mathrm{p}=0.001)$ or kept in the ward $(\mathrm{p}=0.035)$ also substantively differed between both groups.

\section{DISCUSSION}

This study was designed to evaluate the frequency of using surveillance-oriented nursing diagnoses (SOND) and interventions documented in the EHR, in order to reflect nurses' judgments and preventive actions when caring for patients who eventually suffered a cardiac arrest in a hospital ward. Results show almost $60 \%$ of patients had one or more documented SOND before the adverse event. Furthermore, those patients with SOND e-charted received more intensive surveillance practices, with most of them having their ABPP provided every 6 hours or more frequently. This might be an indicator of nurses' acknowledgment and prioritization of those patients' potential problems that might result in a life-threatening complication. The findings also show that more patients might survive a cardiac arrest when compared with patients who had ABPP evaluated every 7 to 12 hours or beyond. This statement is only a description of the results and is not intended to be conclusive, since no causal relationship may be set with the kind of design employed.

Although ABPP is crucial for early detecting acute deterioration, there is no evidence for optimal frequency of their measurement ${ }^{(5,19)}$. Based on professional consensus, some guidelines included recommendations to record vital signs at least twice a day with an interval of 12 hours ${ }^{(5)}$. When considering BP and HR, we found that all patients' charts have had at least a 12 -hour interval vital sign measurement documented, and that half the patients'studied documentation 
showed vital signs at intervals not exceeding every six hours. Despite growing attention towards ABPP and particularly vital signs monitoring as a pillar of surveillance in order to promptly diagnose acute deterioration, nurses are perceived to be neglecting this important intervention ${ }^{(20-21)}$. Minimizing the value of nursing care, routinization and task-oriented nursing care management models are probably some of the factors that are negatively impacting patient care. In a recent root cause analysis on unplanned ICU admissions due to failure or delayed recognition of patients deteriorating in general wards, the authors conclude that almost half these admissions are mostly due to monitoring failures ${ }^{(21)}$. Moreover, the literature on the effectiveness of early warning systems is inconclusive, and more research is needed to explore nurses' intuition and judgment on early recognition of deteriorating patients. It has been said that nurses often intuitively recognize patients who are deteriorating or may decline, rather than by routine measurement of vital signs or other $\mathrm{ABPP}^{(18,22)}$. Nurses' intuition is based on clinical expertise and critical thinking, both related to judgment or diagnostic ability. Underestimating nursing diagnoses, specifically SONDs such as those in the ATIC terminology as potentially powerful tools to contribute to patient safety and outcomes is an outstanding issue.

In our inquiry, mortality rate and sample distribution data in terms of gender, conditions for admission, considering mean age and AACI are consistent with results from previous international studies ${ }^{(13)}$. Our general findings are also coincident with regards to respiratory rate measurement being the most neglected documented vital sign: only $26 \%$ of patients had their respirations e-charted, although the respiratory rate has been considered one of the most sensitive indicators of critical illness and the most specific predictor of serious adverse events ${ }^{(19-21,23)}$.

The findings presented demonstrate the use of SONDs, and illustrate the risk for patients' deterioration leading to major life-threatening or fatal outcomes. Results reflecting the most frequently e-charted SOND in this study moderately correlate with findings in a previous inquiry analyzing the frequency of using the ATIC nursing diagnoses in the general in-patient population ${ }^{(17)}$. In this former study, Risk of arrbythmia, Risk of respiratory failure and Risk of atelectasis were found to be included in patients' care plans with a moderate frequency; Risk of sepsis, Risk of ischemia recurrence/progression and Risk of respiratory failure recurrence/progression were low frequency e-charted nursing diagnoses. These considerations about the similarities and differences between both studies should be interpreted with caution, since they differed in the aims, selected in-patient groups, sample size and design. Published studies on nursing diagnoses and acute deterioration were not found, however several papers on nursing diagnoses and mortality were located and analyzed ${ }^{(24-25)}$.

The first reported four NANDA-I nursing diagnoses: Ineffective respiratory pattern, Impaired spontaneous ventilation, Risk of bleeding and Risk of ineffective gastrointestinal perfusion, as risk factors for death in trauma victims ${ }^{(24)}$. However, the results are based on a small sample and did not include any description on sample characteristics such as age, gender or AACI. Given these potential deficits and the specific critical profile of emergency trauma patients, we decided not to use it for comparison.

The second is a more recent study that explored nursing diagnoses, outcomes and interventions in critical patients, finding 13 nursing diagnoses significantly related with mortality, and the number of diagnoses as an independent predictor of mortality ${ }^{(25)}$. Convenience sampling, sample size, lack of standardized interventions, and absence of randomization limits the generalizability of results. While some NANDA nursing diagnoses in that inquiry such as Impaired gas exchange, Risk for ineffective cerebral tissue perfusion or Risk for decreased cardiac tissue perfusion might be comparable with selected ATIC SONDs found in our results, other NANDA-I diagnoses such as Disturbed sleep pattern or Impaired oral mucous membrane have no comparison in our findings. In any case, these authors explored the relationship between nursing diagnoses and mortality in critical care patients, while our study is based on acute adult patients in nursing wards, so a comparison is probably inconsistent.

In the absence of other research articles relating nursing diagnoses and patients' serious adverse events to compare, studies focusing on the relationship between mortality and nursing documentation were addressed ${ }^{(13,26)}$. In one of these studies ${ }^{(26)}$, the patients' profiles are consistent with ours in terms of gender distribution and differed in aged population and a lower proportion of patients initially admitted to ICU in our study; while the sample profile was considerably different in the other ${ }^{(13)}$, also showing a younger mean age but a higher mean AACI. Neither of these two studies included nursing diagnoses; although, descriptors of the deterioration causes leading to death are identified in one of them, including respiratory failure, septic shock, cardiac arrest, cardiac shock or hemorrhage ${ }^{(26)}$. These descriptors might be comparable with our findings on SONDs documented by nurses in the e-care plans. In our inquiry, the proportion of patients with e-documented SONDs who finally died was found to be significantly lower when compared to patients who did not have any SOND e-charted. This does not mean that SONDs have a real direct effect on patient's mortality, but they are probably contributing to reinforce existing surveillance efforts.

The content of nursing documentation has been closely associated with nurses' professional knowledge and clinical expertise $^{(27-28)}$. Thus, it could be hypothesized that when a SOND is found in a care plan, it may indicate ward nurses' proficiency to advance what might happen, intensify vigilance efforts and foster early detection of acute deterioration. However, further studies are needed to clarify these issues. In addition, the difference in the number of deceased patients between groups could be age-related, yet older patients' outcomes may be worse than those of younger ones, reflecting additional underlying vulnerability; however, age should not be a justification to lessen nursing surveillance efforts, since aging does not necessarily correlate with palliation as a single goal.

In our study, the frequency of ABPP measurements also differed between groups. Patients in the NO SOND group were older, received less nursing surveillance and their final outcomes were worse. It is important to note that these data might be indicating the need for exploring the possibility to set 
standards of vital sign measurement frequency and other ABPP considering age, condition for admission, AACI and SONDs, because these variables seem to be related with increased risk for patients, although further work is required to gain a more complete understanding and to draw up clearer conclusions.

Our findings on the frequency of ABPP recording do not necessarily reflect the number of times a nurse is in contact with a patient, surely it is higher ${ }^{(23)}$. However, being in the room of a patient to attend a call, administer drugs, perform personal care or complex procedures is not synonymous with surveillance. Nurses are able to manage their workload while effectively being observant to the patient's status, and the time required to provide basic care or advanced procedures is an opportunity to identify changes in their status. Nevertheless, there is no evidence to our knowledge supporting this statement, and it cannot be proven with such a design presented.

The ATIC SONDs were originally designed considering attributes of natural language to ease clinicians' communication and foster patient safety ${ }^{(16)}$. They signal patients' vulnerability as expressed by the "Risk for" part of the label, and most of them implicitly express two recognized surveillance attributes, namely temporary and cumulative effect, as reflected in the use of the words "progression" (which implies that the condition exits and may worsen), "recurrence" (indicating the condition has existed and may occur again) or both ${ }^{(16-17)}$. In the hospital setting care is not provided by a single nurse, but by multiple nurses who differ in educational background, experience and expertise; ATIC SONDs may serve more expert nurses to better reflect their judgments on the patient's status, while at the same time they may be useful to guide the learning process of novice and advanced beginner nurses to achieve surveillance competency. However, more studies are needed to clarify this and other considerations on SONDs, including an evaluation of the differences among novice and expert nurses' understanding and usage patterns of these nursing diagnoses and interventions.

Our study has the inherent limitations to a retrospective, cross-sectional design. Another limitation of this inquiry is that it did not consider type of admission: scheduled or urgent. Among acutely admitted patients who arrive to the emergency department with normal vital signs, it has been described that more than $30 \%$ exhibit signs of deterioration within 24 hours $^{(29)}$. Finally, most of the published studies on preventing acute deterioration do not consider significant cues, or organizational and contextual variables involved in recording vital signs. Our inquiry did not consider the retrospective evaluation of the presence of potential triggers or cues to deterioration in the e-charts other than ABPP, and it also did not address organizational issues, but it is probably the first study observing SOND surveillance practices in terms of ABPP measurements and final outcomes in patients who experienced a cardiac arrest in a hospital ward.

\section{CONCLUSION}

ATIC surveillance oriented nursing diagnoses are frequently found e-charted by ward nurses in the care plans of those acute in-patients who eventually suffered a cardiac arrest. Surveillance interventions are provided more often in those patients who had a documented SOND, with interval frequencies of assessments not exceeding every 6 hours. At these intervals, more patients survive a cardiac arrest when compared to survival in patients without documented SONDs and who received less intensive nursing surveillance. Nurses' judgments on patient status or progress as represented with SONDs in the care plans are observed to contribute to the early detection of preventable life-threatening complications.

\section{RESUMO}

Objetivo: Determinar a frequência de registro eletrônico de diagnósticos e intervenções de vigilância no plano de cuidados para pacientes que sofreram uma parada cardíaca durante a admissão e avaliar se existem diferenças com base no perfil do paciente, medidas de monitoramento e resultados. Método: Estudo descritivo, observacional, retrospectivo, transversal, que incluiu dados dos registros eletrônicos de pacientes internados em uma das 107 unidades de oito hospitais de cuidados agudos. Para análise dos dados foram utilizados estatísticos descritivos. Os valores de $\mathrm{p}$ foram relatados em dois ramos. Resultados: Foram obtidos dados de 492 documentos de enfermagem de pacientes que sofreram uma parada cardíaca. Quase 60\% dos prontuários eletrônicos incluídos na análise continham um ou mais diagnósticos de vigilância. Diferenças significativas foram encontradas entre os pacientes com e sem registro desses diagnósticos, no que se refere à frequência das medições dos sinais vitais e aos resultados finais. Conclusão: Os diagnósticos de vigilância podem desempenhar um papel importante na prevenção de deterioração aguda em pacientes adultos hospitalizados.

\section{DESCRITORES}

Diagnósticos de Enfermagem; Parada Cardíaca; Terminologia Padronizada em Enfermagem; Vigilância; Sinais Vitais.

\section{RESUMEN}

Objetivo: Los objetivos de este estudio fueron examinar la frecuencia de los diagnósticos enfermeros basados en la vigilancia y las intervenciones documentadas en los planes de asistencia mediante sistema informático de pacientes que pasaron por paro cardiaco durante estancia hospitalaria y observar si existen diferencias en términos de perfil de los pacientes, medidas de vigilancia y resultados. Método: Descriptivo, observacional, retrospectivo, transversal, randomizado, incluyendo datos de documentación informática de pacientes que pasaron por paro cardiaco durante estancia hospitalaria en cualquiera de las 107 alas adultas de las ocho instalaciones de cuidados intensivos. Las estadísticas descriptivas fueron utilizadas para los análisis de datos. Valores $\mathrm{P}$ bilaterales fueron relatados. Resultados: Casi el 60\% del los pacientes analizados por la gráfica electrónica tuvieron diagnóticos enfermeros de vigilancia representados en los planes de cuidados informatizados. Fueron encontradas diferencias significativas en pacientes que tuvieron dichos diagnósticos documentados y los que no los tuvieron en términos de frecuencia de mediciones de señales vitales y resultados finales. Conclusión: Los diagnósticos enfermeros de vigilancia pueden jugar un rol significativo en la prevención del deterioro agudo de pacientes adultos hospitalizados en las unidades de cuidados intensivos.

\section{DESCRIPTORES}

Diagnósticos de Enfermería; Paro Cardíaco; Terminología Normalizada de Enfermería; Vigilancia; Signos Vitales. 


\section{REFERENCES}

1. Rich K. In-hospital cardiac arrest: pre-event variables and nursing response. Clin Nurs Spec. 1999;13(3):147-53.

2. Churpek MM, Yuen TC, Park SY, Meltzer DO, Hall JB, Edelson DP. Derivation of a cardiac arrest prediction model using ward vital signs. Crit Care Med. 2012;40(7): 2102-8.

3. Thornlow DK, Anderson R, Oddone E. Cascade iatrogenesis: factors leading to the development of adverse events in hospitalized older adults. Int J Nurs Stud. 2009; 46(11):1528-35.

4. Odell M, Victor C, Oliver D. Nurses' role in detecting deterioration in ward patients: systematic literature review. J Adv Nurs. 2009;65(10):1992-2006.

5. Armitage M, Eddleston J, Stokes T; Guideline Development Group. Recognising and responding to acute illness in adults in hospitals: summary of the NICE guidance. BMJ. 2007;335 (7613):258-9.

6. The Joint Commission; Accreditation Hospital. National Patient Safety Goals [Internet]. Oakbrook Terrace, Illinois; 2016 [cited 2017 Jan 15]. Available from: https://www.jointcommission.org/assets/1/6/2016_NPSG_HAP_ER.pdf

7. Kutney-Lee A, Lake ET, Aiken LH. Development of the hospital nurse surveillance capacity profile. Res Nurs Health. 2009;32(2):217-28.

8. Voepel-Lewis T, Pechlavanidis E, Burke C, Talsma AN. Nursing surveillance moderates the relationship between staffing levels and pediatric postoperative serious adverse events: A nested case-control study. Int J Nurs Stud. 2013;50(7):905-13.

9. McHugh MD, Stimpfel AW. Nurse reported quality of care: a measure of hospital quality. Res Nurs Health. 2012;35(6):566-75.

10. Saranto K, Kinnuen UM. Evaluating nursing documentation, research designs and methods: systematic review. J Adv Nurs. 2009;65(3):464-76.

11. Shever LL. The impact of nursing surveillance on failure to rescue. Res Theory Nurs Pract. 2011;25(2):107-26.

12. Collins SA, Vawdrey DK. "Reading between the lines" of flow sheet data: nurses' optional documentation associated with cardiac arrest outcomes. Appl Nurs Res. 2012; 25(4):251-7.

13. Collins SA, Cato K, Albers D, Scott K, Stetson PD, Bakken S, et al. Relationship between nursing documentation and patients' mortality. Am J Crit Care. 2013;22(4): 306-12.

14. Carrington JM, Effken JA. Strengths and limitations of the electronic health record for documenting clinical events. Comput Inform Nurs. 2011;29(6):360-7.

15. NANDA International. Diagnósticos enfermeros: definiciones y clasificación 2015-2017. Barcelona: Elsevier; 2015.

16. Juvé-Udina ME. ATIC: eje diagnóstico. Barcelona: Naaxpot SLU; 2016.

17. Juvé-Udina ME. What patients' problems do nurses e-chart? Longitudinal study to evaluate the usability of an interface terminology. Int J Nurs Stud. 2013;50(12):1698-710.

18. Juvé-Udina ME, Zuriguel-Perez E, Fabrellas-Padres N, Gonzalez-Samartino M, Castellà-Creus, Romero-García M, et al. Basic nursing care: retrospective evaluation of communication and psychosocial interventions documented by nurses in the acute care setting. J Nurs Scholarsh. 2014;46(1):65-72

19. Stevenson JE, Israelsson J, Nilsson GC, Petersson GI, Bath PA. Recording signs of deterioration in acute patients: the documentation of vital signs within electronic health records in patients who suffered in-hospital cardiac arrest. Health Inform J. 2016;22(1):21-33.

20. Mok W, Wang W, Cooper S, Ang ENK, Liaw SY. Attitudes toward vital signs monitoring in the detection of clinical deterioration: scale development and survey of ward nurses. Int J Qual Health Care. 2015;27(3):207-13.

21. Van Galen LS, Struik PW, Driesen BE, Merten H, Ludikhuize J, van der Spoel Jl, et al. Delayed recognition of deterioration of patients in general wards is mostly caused by human related monitoring failures: root cause analysis of unplanned ICU admissions. PLoS One. 2016;11(8):e0161393.

22. Douw G, Schoonhoven L, Holwerda T, Huisman-de Wall G, van Zanten ARH, van Achterberg T, et al. Nurses' worry or concern and early recognition of deteriorating patients on general wards in acute care hospitals: a systematic review. Crit Care. 2015; 20(19):230-41.

23. Cardona-Morrell M, Prgomet M, Lake R, Nicholson M, Harrison R, Long J, et al. Vital signs monitoring and nurse-patient interaction: a qualitative observational study of hospital practice. Int J Nurs Stud. 2016;56:9-16.

24. Sallum AM, Santos JL, Lima FD. Nursing diagnoses in trauma victims with fatal outcomes in the emergency scenario. Rev Lat Am Enfermagem. 2012;20(1):3-10.

25. Castellan C, Sluga S, Spina E, Sanson G. Nursing diagnoses, outcomes and interventions as measures of patient complexity and nursing care requirement in Intensive Care Unit. J Adv Nurs. 2016;72(6):1273-86.

26. De Meester K, Van Bogaert P, Clarke SP, Bossaert L. In-hospital mortality after serious adverse events on medical and surgical nursing units: a mixed methods study. J Clin Nurs. 2012;22(15-16):2308-17.

27. Nascimento RA, Assunção MS, Silva Junior JM, Amendola CP, Carvalho TM, Lima EQ, et al. Nurses' knowledge to identify early acute kidney injury. Rev Esc Enferm USP. 2016;50(3):399-404. DOI: http://dx.doi.org/10.1590/S0080-623420160000400004

28. Wang N, Hailey D, Yu P. Quality of nursing documentation and approaches to its evaluation: a mixed-method systematic review. J Adv Nurs. 2011;67(9):1858-75.

29. Henriksen DP, Brabrand M, Lassen AT. Prognosis and risk factors for deterioration in patients admitted to a medical emergency department. PLoS One. 2014;9(4):e94649. 